\title{
A Novel Application of Natural Peat for Solid-Phase Extraction of Pyrimethanil, Flumetralin, and Kresoxim-Methyl in Water Using Gas Chromatography-Mass Spectrometry
}

\author{
Alex S. M. S. J. Santos, Adriano Aquino, Luciane P. C. Romão, and Sandro Navickiene \\ Department of Chemistry, Federal University of Sergipe, Avenida Marechal Rondon s/no, \\ 49100-000 São Cristóvão, SE, Brazil \\ Correspondence should be addressed to Sandro Navickiene, sandnavi@ufs.br
}

Received 12 March 2012; Accepted 6 May 2012

Academic Editors: A. Namera and A. Vazquez

Copyright () 2012 Alex S. M. S. J. Santos et al. This is an open access article distributed under the Creative Commons Attribution License, which permits unrestricted use, distribution, and reproduction in any medium, provided the original work is properly cited.

Natural peat was tested for extraction of pyrimethanil, flumetralin, and krexosim-methyl from water, with analysis using gas chromatography-mass spectrometry (GC-MS) in selected ion monitoring mode (SIM). Experiments were carried out at one fortification level $\left(0.1 \mu \mathrm{g} \mathrm{L}^{-1}\right)$ and resulted in recoveries in the range $41-96 \%$, with RSD values between 6.8 and $12.6 \%$ for natural peat as sorbent. Detection and quantification limits ranged from 0.02 to $0.05 \mu \mathrm{g} \mathrm{L}^{-1}$ and from 0.07 to $0.1 \mu \mathrm{g} \mathrm{L}^{-1}$, respectively, for the different pesticides studied. The method developed was linear over the range tested $\left(0.07-4.0 \mu \mathrm{g} \mathrm{L}^{-1}\right)$, with correlation coefficients ranging from 0.9919 to 0.9989 . Comparison between peat and commercial sorbents $\left(\mathrm{C}_{18}\right.$-bonded silica, ENVI-Carb, Florisil, silica gel, ENVI-Carb/LC-NH 2 ) showed better performance of peat sorbent for flumetralin and kresoxim-methyl.

\section{Introduction}

In recent years, research into new materials for the extraction and purification of organic compounds has also been stimulated by the growing interest in environmental preservation and human health protection $[1,2]$. In view of this, natural peat is a sedentarily accumulated material consisting of dead organic matter in the waterlogged environment. Due to the high content of humic substances, natural peat exhibits favorable physicochemical properties enabling the application in various technical areas, for instance, wastewater treatment, pollution monitoring, fuel production, soil fertilizing, and veterinary and human medicine [3]. Peat, as an adsorbent, is a porous material with highly polar character because it carries polar functional groups such as alcohols, aldehydes, carboxylic acids, ketones, and phenolic hydroxides, which can adsorb large quantities of metals, dyes, and other organic molecules, whose adsorption capacity is comparable to conventional extracting phase like activated carbon, silica gel, or alumina $[4,5]$. However, no studies of the use of peat material for solid-phase extraction of pesticides in water have been reported. For the control of level concentration of pesticide residues in water, the Ministry of Health in Brazil established the value maximum allowable by decree number 518 on March 25, 2004 [6]. For environmental and drinking water, the maximum admissible concentration of a single compound established by the European Union (EU) is $0.1 \mu \mathrm{g} \mathrm{L}^{-1}$, and $0.5 \mu \mathrm{g} \mathrm{L} \mathrm{L}^{-1}$ is the maximum allowed for the total concentration of all pesticides $[7,8]$.

The aim of this study was to evaluate the performance of the natural peat as an alternative sorbent for the solid-phase extraction of the pesticides from water samples with analysis using gas chromatography-mass spectrometry (GC-MS). The pesticides of interest are pyrimethanil (anilinopyrimidine), flumetralin (dinitroaniline), and krexosim-methyl (strobilurin) which are typically used in our region. Figure 1 shows the molecular structures of the pesticides studied. 
<smiles>Cc1cc(C)nc(Nc2ccccc2)n1</smiles>

Pyrimethanil

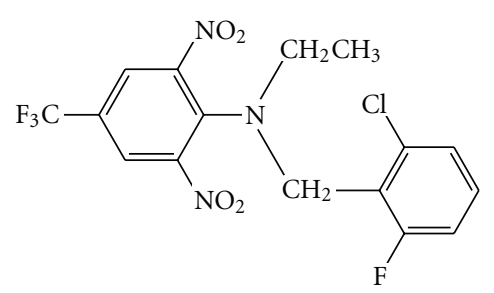

Flumetralin<smiles>CO/N=C(/C(=O)OC)c1ccccc1COc1ccccc1C</smiles>

Kresoxim-methyl

FIGURE 1: Molecular structures of pesticides studied.

\section{Experimental}

2.1. Chemicals, Reagents, and Supplies. Certified standards of pyrimethanil, flumetralin, and krexosim-methyl were purchased from Dr. Ehrenstorfer (Augsburg, Germany). All standards were at least $97 \%$ pure. Stock and working standard solutions of the pesticides were prepared by precisely weighing out and then dissolving the compounds in dichloromethane solvent, pesticide grade, obtained from Tedia (Fairfield, OH, USA). Strata $\mathrm{C}_{18}$-bonded silica $(50 \mu \mathrm{m})$, Strata SI-1 silica $(55 \mu \mathrm{m})$ and Strata FL-PR Florisil were obtained from Phenomenex (Torrance, CA, USA) and ENVI-Carb and ENVI-Carb/LC-NH $\mathrm{N}_{2}$ from Supelco (Bellefonte, PA, USA). These cartridges were of $6 \mathrm{~mL}$ capacity packed with $500 \mathrm{mg}$ of solid-phase. The vacuum manifold from Supelco was used to perform the SPE.

2.2. Peat Material Preparation. Raw peat samples were collected from peatland located in the municipality of Santo Amaro das Brotas, State of Sergipe, Brazil. The samples were air-dried at room temperature as recommended in the literature, sieved through a 48-mesh grid, and then stored in jars at room temperature. The water samples used for the blank and fortified studies were obtained from an uncontaminated reservoir.

2.3. Extraction Procedure. The amount of $250 \mathrm{mg}$ of peat material was transferred to the cartridge containing a Teflon frit at the bottom. A second frit was placed on top to immobilize this sorbent. The peat material of the SPE cartridge was preconditioned with $5.0 \mathrm{~mL}$ of dichloromethane, $5 \mathrm{~mL}$ of methanol followed by $10 \mathrm{~mL}$ of water. It was placed on top of a vacuum block. An analytical aliquot of $500 \mathrm{~mL}$ water was transferred to the polypropylene cartridge at a flow rate of ca. $0.5 \mathrm{~mL} \mathrm{~min}^{-1}$ and allowed the solid phase to dry for $10 \mathrm{~min}$. The pesticides were eluted with $10 \mathrm{~mL}$ of dichloromethane and concentrated to $1 \mathrm{~mL}$ with nitrogen stream. A $1 \mu \mathrm{L}$ portion of the extract was then directly analyzed by GC-MS.

2.4. GC-MS System and Operating Conditions. For the identification and quantification of the pesticides, a Shimadzu (Kyoto, Japan) system consisting of a QP-2010plus mass spectrometer coupled to a GC-2010 gas chromatograph with a Shimadzu AOC 20i autosampler and a split/splitless injector was used. A fused-silica DB-5MS column (5\% phenyl and 95\% polydimethylsiloxane; $30 \mathrm{~m} \times 0.25 \mathrm{~mm} \mathrm{ID}, 0.25 \mu \mathrm{m})$, supplied by J \& W Scientific (Folsom, CA, USA), was employed with helium (purity 99.995\%) as carrier gas at a flow rate of $1.2 \mathrm{~mL} \mathrm{~min}^{-1}$. The column temperature was programmed as follows: $50^{\circ} \mathrm{C}$ for $1 \mathrm{~min}$, then directly to $290^{\circ} \mathrm{C}$ at $10^{\circ} \mathrm{C} / \mathrm{min}$, with a hold time of $3 \mathrm{~min}$. The solvent delay was $5 \mathrm{~min}$. The injector port was maintained at $250^{\circ} \mathrm{C}$ and a $1 \mu \mathrm{L}$ sample volume was injected in splitless mode $(0.7 \mathrm{~min})$. The data were acquired and processed on a personal computer, using Shimadzu GC Solution software. The total analysis time was $27 \mathrm{~min}$, and the equilibrium time was $2 \mathrm{~min}$. The eluent from the GC column was transferred, via an interface line heated to $280^{\circ} \mathrm{C}$, into the $70 \mathrm{eV}$ electron ionization source, also maintained at $280^{\circ} \mathrm{C}$. The analysis was performed in the selected ion monitoring (SIM) mode. The ions monitored were $m / z 183,197$, and 198 (pyrimethanil), $\mathrm{m} / z$ 143, 157, 404 (flumetralin), and $\mathrm{m} / z$ 116, 206, and 282 (kresoxim-methyl). Values of $\mathrm{m} / \mathrm{z}$ in bold type correspond to the quantification ion for each pesticide, Figure 2.

2.5. Characterization of Peat Material. For the characterization of peat material, a Carlo Erber 1110 elemental analyser was used to determine the elemental compositions of the peat samples. Detailed mineralogical studies of peat samples were carried out using X-ray diffraction (Siemens D-5000), with step time $1 \mathrm{~s}$, step size $0.05 \mathrm{dg}$, and wavelength $1.54 \mathrm{~A}$. 
TABLE 1: Influence of different sorbents on pesticide recoveries (RSD\%) using dichloromethane as eluting solvent during SPE procedure with GC-MS analysis. Water samples spiked at $2.5 \mu \mathrm{g} \mathrm{L} \mathrm{L}^{-1} *(n=7)$.

\begin{tabular}{lccc}
\hline Sorbent & & Recovery (\%) \pm RSD (\%) & Kresoxim-methyl \\
\hline C $_{18}$-bonded silica & Pyrimethanil & Flumetralin & $80 \pm 8.8$ \\
Florisil & $102 \pm 5.2$ & $79 \pm 6.1$ & $14 \pm 0.3$ \\
Silica gel & $39 \pm 1.4$ & $80 \pm 4.3$ & $17 \pm 0.2$ \\
ENVI-Carb & $7 \pm 0.3$ & $70 \pm 1.6$ & $80 \pm 7.4$ \\
ENVI-Carb/LC-NH & $74 \pm 6.7$ & $73 \pm 1.4$ & $52 \pm 2.7$ \\
\hline
\end{tabular}

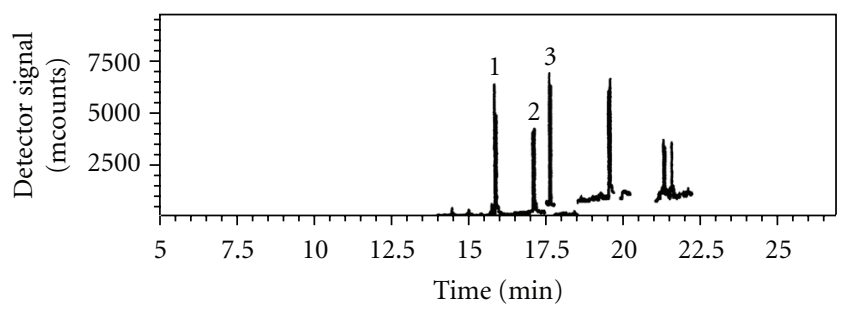

(a)

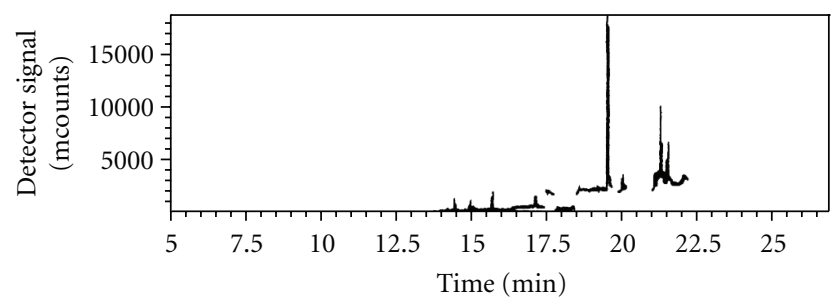

(b)

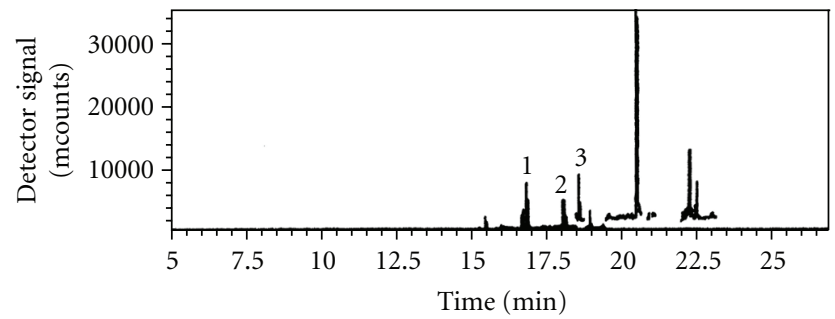

(c)

FIGURE 2: GC-MS (SIM mode) chromatograms of (a) typical water extract fortified at a concentration level of $0.1 \mu \mathrm{g} \mathrm{L}-1$; (b) water control sample; (c) standard mixture solution at a concentration level of $0.1 \mu \mathrm{g} \mathrm{L}^{-1}$. The numbered peaks are as follows: (1) pyrimethanil (16.9 $\mathrm{min}$ ); (2) flumetralin (18.1 min); (3) kresoximmethyl (18.6 min). See Section 2 for details on the GC-MS system and operating conditions.

The experimental XRD patterns have been indexed using the international JCPDF (Joint Committee for Powder Diffraction Files) database, searchable by the position of the $\mathrm{X}$-ray diffraction peaks.

\section{Results and Discussion}

3.1. Characterization of Peat Material. The elemental analyses of the tropical peat from Santo Amaro das Brotas showed
TABLE 2: Comparison of average \% recoveries (RSD\%) of fortified pesticides in water from SPE method using natural peat and $\mathrm{C}_{18^{-}}$ bonded silica as solid-phase material $*(n=7)$.

\begin{tabular}{lcc}
\hline \multirow{2}{*}{ Pesticide } & \multicolumn{2}{c}{ Recovery $(\%) \pm \mathrm{RSD}(\%)^{*}, 0.1 \mu \mathrm{g} \mathrm{L}^{-1}$} \\
& $\mathrm{C}_{18}$-bonded silica & Natural peat \\
\hline Pyrimethanil & $105 \pm 7.2$ & $41 \pm 12.6$ \\
Flumetralin & $77 \pm 6.3$ & $96 \pm 7.2$ \\
Kresoxim-methyl & $90 \pm 8.8$ & $88 \pm 6.8$ \\
\hline
\end{tabular}

the values $\mathrm{C}(53.1 \%), \mathrm{H}(6.0 \%), \mathrm{O}(31.5 \%)$, and dry ash $(9.4 \%)$. Typical compositions of peat are in the range $40-$ $60 \% \mathrm{C}$ and $4-6 \% \mathrm{H} \mathrm{[3].} \mathrm{The} \mathrm{elemental} \mathrm{ratios} \mathrm{H} / \mathrm{C}$ (1.3) and $\mathrm{O} / \mathrm{C}(0.4)$ are indicators for the percentage saturation of the $\mathrm{C}$ atoms within the organic molecule and of the carbohydrate content, respectively. Lower $\mathrm{H} / \mathrm{C}$ ratios indicate higher aromaticity in the samples. The lowest $\mathrm{O} / \mathrm{C}$ ratio of the peat sample indicates the lowest carbohydrate level and/or the highest organic content of that sample peat. The estimate value of the organic matter was $96 \%$ for the peat sample [3]. The XRD of peat sample is characteristic of amorphous matter with a hump, between $18^{\circ}$ and $32^{\circ}$. Bozkurt et al. analyzing the processes involved in peat formation, recognized an anaerobic thick structural layer, which is formed of residual material from the original plant structure, decay products and new substances produced mainly by bacteria [9]. At this level, peat would be amorphous and highly humified. However, only the XRD of dry ash or residue of that sample revealed mineral characteristics with presence of quartz mineral and some clay material. These materials were covered by organic matter of peat. The combination of the elemental analyses and XRD indicate that the peat studied is highly humified and rich in organic compounds.

3.2. SPE Procedure. In this study, the performance of natural peat as an alternative sorbent material for solid-phase extraction (SPE) was compared with different commercial phases, such as $\mathrm{C}_{18}$-bonded silica, Florisil, silica gel, ENVICarb and ENVI-Carb/LC-NH$H_{2}$, to carry out the multiclass analysis of the pesticides pyrimethanil, flumetralin, and kresoxim-methyl in water sample, once the type of the sorbent and the polarity of the elution solvent are known to be key factors in SPE [10]. 
TABLE 3: Calibration data, limits of detection, and limits of quantification for the pesticides in water samples analyzed by GC-MS.

\begin{tabular}{|c|c|c|c|c|}
\hline Pesticide & Regression equation & Determination coefficient & LOD & LOQ \\
\hline Pyrimethanil & $y=2273 x-1930$ & 0.9934 & 0.05 & 0.1 \\
\hline Flumetralin & $y=6560 x-1100$ & 0.9989 & 0.04 & 0.1 \\
\hline Kresoxim-methyl & $y=10464 x-10042$ & 0.9919 & 0.02 & 0.07 \\
\hline
\end{tabular}

Preliminary investigations for optimization of the SPE procedure for the extraction of pesticides from water were performed using water samples spiked with pesticides at $2.5 \mu \mathrm{g} \mathrm{L}^{-1}, \mathrm{C}_{18}$-bonded silica, Florisil, silica gel, ENVI-Carb, and ENVI-Carb/LC- $\mathrm{NH}_{2}$ as solid-phase sorbent and dichloromethane as eluting solvent. When comparing the data obtained, rather different results were found for these systems. In the experiments carried out with ENVI-Carb/LC-NH $\mathrm{NH}_{2}$ sorbent, it was noted that kresoximmethyl, pyrimethanil and flumetralin pesticides gave very low recovery $(<70 \%)$, while Florisil and silica gel with the elution of the SPE column with dichloromethane produced adequate recovery for flumetralin in both systems (>70\%), however, kresoxim-methyl and pyrimethanil were not recovered. To evaluate the influence of the eluting solvent, dichloromethane and acetone were tested as eluting solvent. When comparing the data obtained, rather different results were found for the solvents tested. Dichloromethane was selected, because it presented the cleanest extracts for the pesticide extraction from the water matrix. Based on these experiments, $\mathrm{C}_{18}$-bonded silica and ENVI-Carb sorbents were investigated to minimize coextraction of matrix interferences using the same eluting solvent. The SPE procedure prepared with these sorbents produced extracts that show minimal interferences for most of the pesticides studied, while the use of ENVI-Carb and dichloromethane for SPE method produces recoveries between $73-80 \%$ for the pesticides, $\mathrm{C}_{18}$-bonded silica sorbent provided recovery values for pyrimethanil, kresoxim-methyl, and flumetralin better to the ones obtained with $\mathrm{C}_{18}$-bonded silica, 79-102\%. Overall results indicate that the combination of $\mathrm{C}_{18}$-bonded silica as solid-phase and dichloromethane as elution solvent is a suitable extraction procedure for determination of pyrimethanil, flumetralin and kresoxim-methyl in a matrix such as water as shown in Table 1. Once the factors that affect the SPE procedure had been optimized, validation of the method was performed. For both solid-phase materials, $\mathrm{C}_{18}$-bonded silica and natural peat, recovery data were calculated by comparison with the appropriate working standard solutions. Recovery experiments were carried out at one fortification level $\left(0.1 \mu \mathrm{g} \mathrm{L}^{-1}, n=7\right)$. Analyses were performed by GC-MS, with external calibration. Average recoveries ranged from 77 to $105 \%$, with relative standard deviations (RSD) of 6.3 to $8.8 \%$ using $\mathrm{C}_{18}$-bonded silica as sorbent, and from 41 to $96 \%$, with RSD values of 6.8 to $12.6 \%$, using natural peat. The values obtained were generally satisfactory, considering the recovery range normally considered acceptable (70-110\%) [11]. Comparison of natural peat with the commercially available $\mathrm{C}_{18}$-bonded silica showed that peat was a similar extracting phase for flumetralin and kresoxim-methyl, using a small amount of the extracting phase $(250 \mathrm{mg})$ instead of the amount of $500 \mathrm{mg}$ of $\mathrm{C}_{18}$-bonded silica. However, recoveries of pyrimethanil presented lower recovery values for natural peat in comparison to the $\mathrm{C}_{18}$-bonded silica solid-phase. Table 2 presents recoveries of the pesticides in water samples using natural peat as solid-phase material.

The linearity for all compounds was determined using blank samples fortified at eight concentration levels (0.07, $0.10,0.20,0.50,1.0,2.0,3.0$, and $\left.4.0 \mu \mathrm{g} \mathrm{L}^{-1}\right)$. At each analyte amount, two replicate measurements were made. The slope and intercept values, together with their standard deviations, were determined using regression analyses. Linear regression coefficients for the different pesticides ranged from 0.9919 to 0.9989 . The limits of detection (LOD) were calculated considering the standard deviation of the analytical noise (a value of seven times the standard deviation of the blank) and the slope of the regression line, and ranged from 0.02 to $0.05 \mu \mathrm{g} \mathrm{L}^{-1}$. The limits of quantification (LOQ) were determined as the lowest concentration giving a response of ten times the average of the baseline noise, calculated using seven unfortified samples. The LOQ values for these compounds ranged from 0.07 to $0.10 \mu \mathrm{g} \mathrm{L}^{-1}$ (Table 3). The repeatability of the method was assessed using six successive analyses of $1.0 \mu \mathrm{g} \mathrm{L}^{-1}$ of pesticide standard solution, and resultant relative standard deviations were in the range of $4.3-6.5 \%[12]$.

3.3. Real Sample Analysis. The developed method was tested with real water samples. Three water samples were collected in the city of São Cristóvão, SE, Brazil. External calibration was used for quantification. The blanks, standards, and samples were processed under the same analytical conditions using $\mathrm{C}_{18}$-bonded silica and peat as sorbents for SPE procedure. No pesticides were detected in any of the samples analyzed.

\section{Conclusions}

The focus of this work was to explore the scientific and technological feasibility of application of different materials as solid-phase sorbent. For the first time ever, peat material was used as solid-phase material for the extraction of pyrimethanil, flumetralin, and kresoxim-methyl in water sample. SPE was demonstrated as a suitable preparation technique for the isolation of the compounds under study from water samples, obtaining good recoveries and precision. 
Economic aspects were not a primary concern, but they are nonetheless important. In this regard, the operational cost of the peat material was much lower compared to other commercial sorbents such as $\mathrm{C}_{18}$-bonded silica. The cost of the peat material was ca. US\$ $0.09 \mathrm{~kg}^{-1}$, considerably less than that of commercial $\mathrm{C}_{18}$-bonded silica (ca. US\$ $4500 \mathrm{~kg}^{-1}$ ). Finally, this method may be useful as a screening protocol to identify pesticides in water by official regulatory laboratories since peat material is cheaper than commercial sorbents.

\section{Acknowledgments}

The authors wish to thank MCT/CNPq and CAPES for financial support of this study.

\section{References}

[1] A. S. Barreto, A. Aquino, S. C. S. Silva et al., "A novel application of mesoporous silica material for extraction of pesticides," Materials Letters, vol. 65, no. 9, pp. 1357-1359, 2011.

[2] H. V. P. De Carvalho, A. M. D. De Jesus, V. M. Prata, D. S. S. Bezerra, L. P. C. Romão, and S. Navickiene, "Tropical peat as a versatile material for solid-phase extraction of pesticides from medicinal plant Cordia salicifolia," Journal of the Brazilian Chemical Society, vol. 21, no. 4, pp. 659-664, 2010.

[3] L. P. C. Romão, J. R. Lead, J. C. Rocha et al., "Structure and properties of Brazilian peat: analysis by spectroscopy and microscopy," Journal of the Brazilian Chemical Society, vol. 18, no. 4, pp. 714-720, 2007.

[4] D. Mohan and C. U. Pittman Jr., "Activated carbons and low cost adsorbents for remediation of tri- and hexavalent chromium from water," Journal of Hazardous Materials, vol. 137, no. 2, pp. 762-811, 2006.

[5] A. N. Fernandes, C. A. P. Almeida, C. T. B. Menezes, N. A. Debacher, and M. M. D. Sierra, "Removal of methylene blue from aqueous solution by peat," Journal of Hazardous Materials, vol. 144, no. 1-2, pp. 412-419, 2007.

[6] Ministry of Health ofBrazil, September 2011, http://dtr2001 saude.gov.br/sas/PORTARIAS/Port2004/GM/GM-518.htm.

[7] Environmental Protection Agency, November 2011, http:// www.epa.gov/pesticides/about/.

[8] P. S. Chen and S. D. Huang, "Determination of ethoprop, diazinon, disulfoton and fenthion using dynamic hollow fiberprotected liquid-phase microextraction coupled with gas chromatography-mass spectrometry," Talanta, vol. 69, no. 3, pp. 669-675, 2006.

[9] S. Bozkurt, M. Lucisano, L. Moreno, and I. Neretnieks, "Peat as a potential analogue for the long-term evolution in landfills," Earth Science Reviews, vol. 53, no. 1-2, pp. 95-147, 2001.

[10] J. Pawliszyn and H. L. Lord, Handbook of Sample Preparation, John Wiley \& Sons, Hoboken, NJ, USA, 1st edition, 2010.

[11] L. Tolosa, J. W. Readman, and L. D. Mee, "Comparison of the performance of solid-phase extraction techniques in recovering organophosphorus and organochlorine compounds from water," Journal of Chromatography A, vol. 725, no. 1, pp. 93106, 1996.

[12] D. M. Bliesner, Validating Chromatographic Methods - A Practical Guide, John Wiley \& Sons, Hoboken, NJ, USA, 1st edition, 2006. 


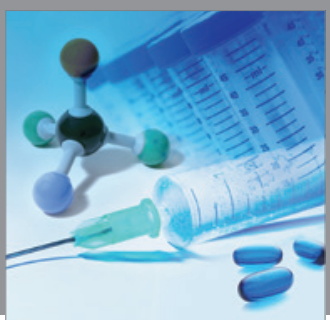

International Journal of

Medicinal Chemistry

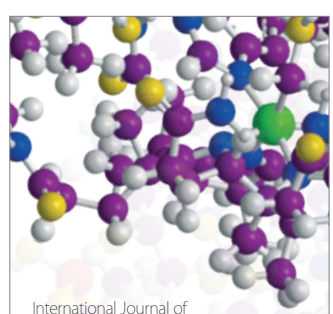

Carbohydrate Chemistry

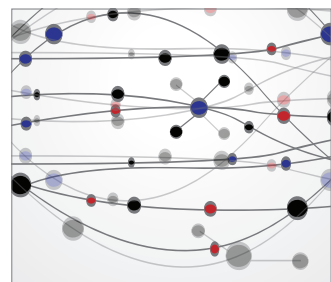

The Scientific World Journal
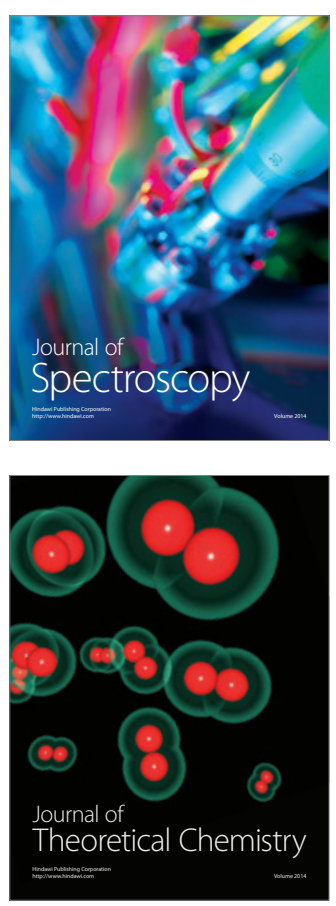
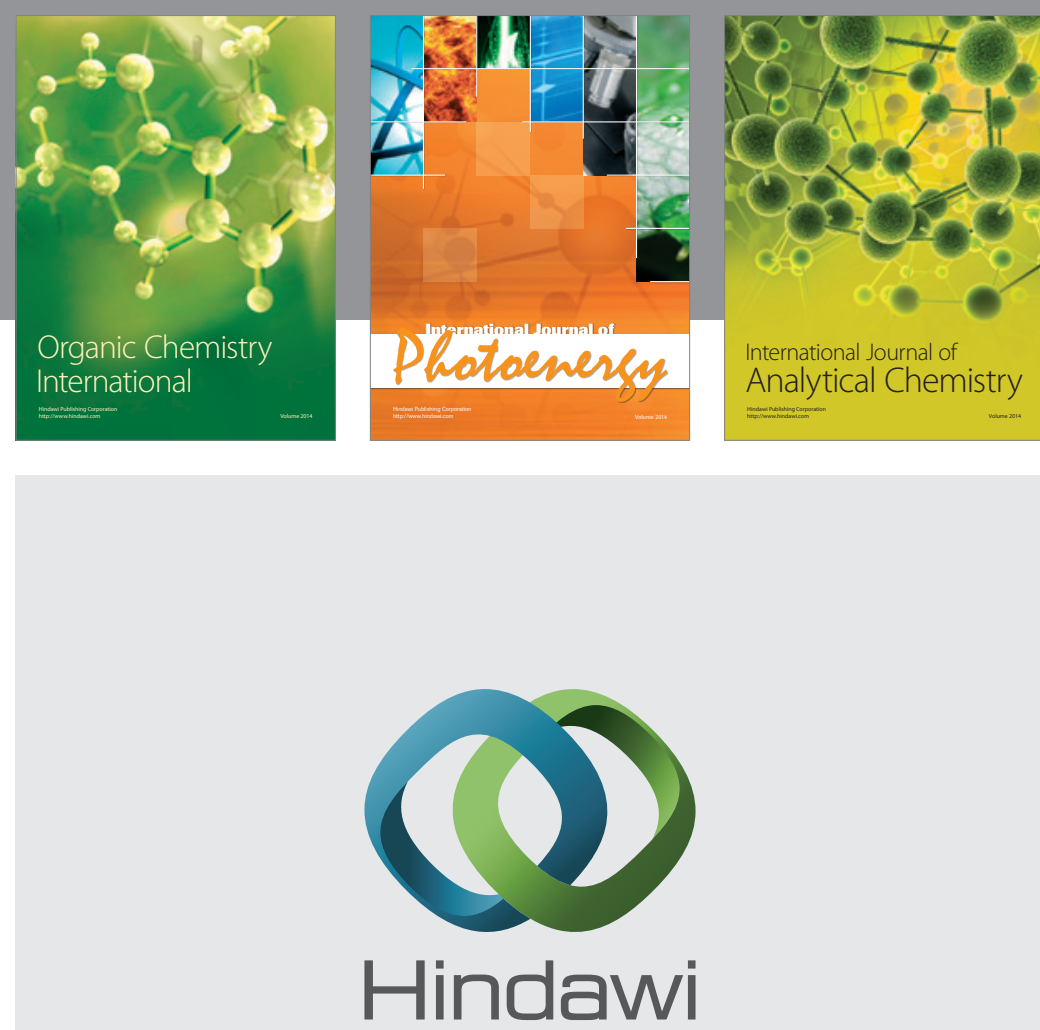

Submit your manuscripts at

http://www.hindawi.com
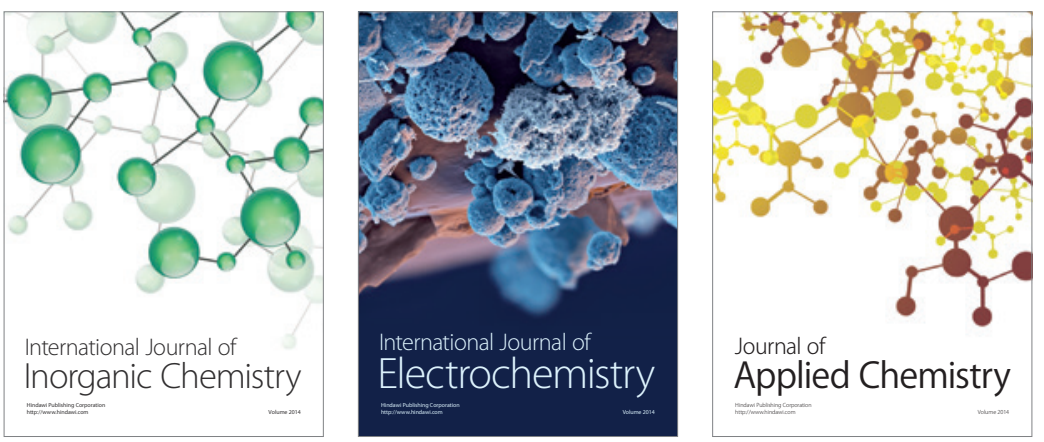

Journal of

Applied Chemistry
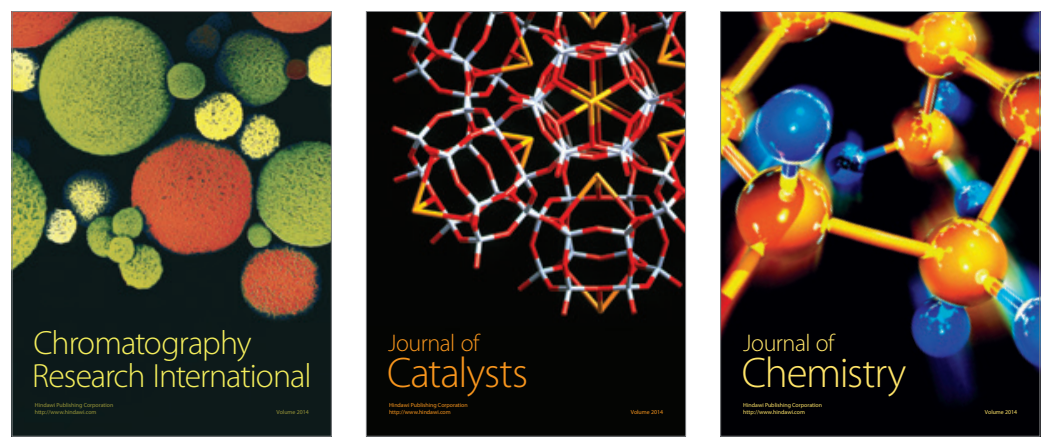
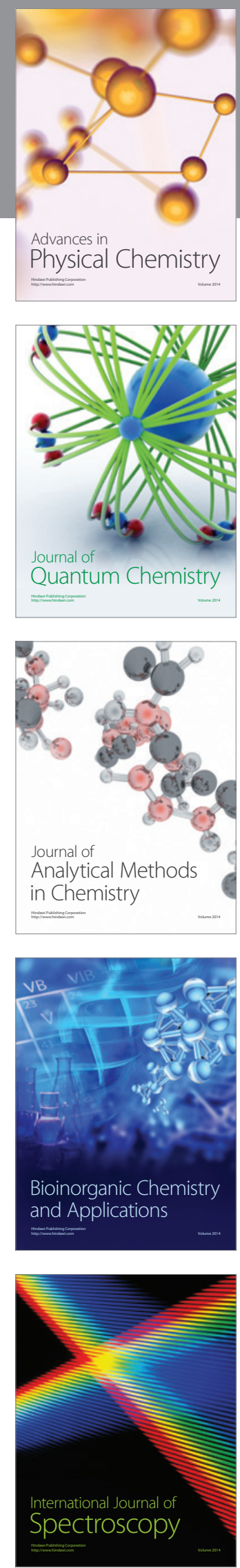